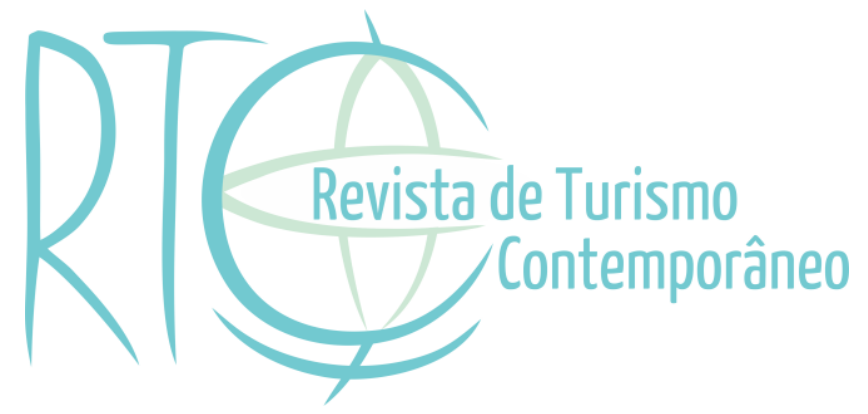

\title{
Planejamento turístico: aspectos teóricos e conceituais e suas relações com o conceito de turismo
}

\section{Tourism planning: theoretical and conceptual aspects and their relationship with the concept of tourism}

\section{Paula Wabner Binfaré}

Doutoranda pelo Programa de Pós-Graduação em Turismo PPGTUR-UFRN. Natal/RN, Brasil E-mail: paulabinfare@gmail.com

\section{Cleber Trindade Castro}

Doutorando pelo Programa de Pós-Graduação em Turismo PPGTUR-UFRN. Natal/RN, Brasil E-mail: cleber.castro@hotmail.com

\section{Michel Vieira Silva}

Doutorando pelo Programa de Pós-Graduação em Turismo PPGTUR-UFRN. Natal/RN, Brasil E-mail: micheljvs@hotmail.com

\section{Patrícia Lins Galvão}

Doutoranda pelo Programa de Pós-Graduação em Turismo PPGTUR-UFRN. Natal/RN, Brasil E-mail: parroxelas@yahoo.com

\section{Sinthya Pinheiro Costa}

Doutoranda pelo Programa de Pós-Graduação em Turismo PPGTUR-UFRN. Natal/RN, Brasil E-mail: sinthyap@terra.com.br 


\section{RESUMO}

A atividade turística ganha espaço para novas reflexões no meio acadêmico ao longo dos anos e a cada novo passo que se dá, maior o universo de teorias oriundas de estudiosos do assunto. O planejamento turístico é revisado à medida que novos conhecimentos vêm sendo incorporados por pesquisadores e estudiosos do turismo. Desta forma, o objetivo deste trabalho é analisar aspectos conceituais relacionados às teorias sobre turismo e planejamento turístico, compreendendo as concepções de turismo utilizadas por autores brasileiros que apontam em suas pesquisas etapas de planejamento do turismo em obras sobre este tema específico. Utilizou-se os procedimentos metodológicos de levantamento bibliográfico e análise do conteúdo das principais obras sobre planejamento turístico de autores brasileiros com grande utilização na formação de profissionais turismólogos e que embasam pesquisas sobre o tema, a saber: Barretto (1991), Ruschmann (1997), Beni (1998) e Dias (2003). Observamos uma diversidade de concepções de turismo utilizadas pelos autores analisados, que variam, por exemplo, de entendimentos desse fenômeno como uma atividade comercial o que implica, que o planejamento turístico deve ser o ordenamento do arranjo produtivo para a dinamização econômica do turismo, e, por outro lado, de uma concepção do turismo como atividade humana, que envolve, além de sua dimensão econômica, aspectos socioculturais da interação visitado-visitante, usos turísticos da cultura e do ambiente locais, com suas consequências, que devem ser considerados no planejamento turístico.

Palavras-chave: Turismo. Teoria do Turismo. Planejamento Turístico.

\section{ABSTRACT}

Touristic activities is getting new shapes for new reflections in academic sphere along the years and, each new step, larger are the new theories and scholars arising in this field of study. Touristic planning is reviewed as its new events has been incorporated for researchers and scholars in tourism. This way, the aim of the paper is to analyze the conceptual aspects related to the theories of tourism and touristic planning, understanding the tourism concepts used by Brazilian authors which point in their search stages about tourism planning in this specific topic. The methodology used to develop this study is based on literature review and analyzing the most important studies regarding to this topic for Brazilian authors as Barretto (1991), Ruschmann (1997), Beni (1998) and Dias (2003). We noticed a diverse conception about tourism referred by the authors just mentioned, which vary for instance, from understanding the phenomenon as an economic activities which implies that touristic planning must be ordered from productive arrangement to economic boosting of tourism, and on the other hand, a conception of tourism as human activity which envolves, beyond the economic dimension, socio-cultural aspects resulted of the interaction from visited-visitor, local culture and environmental touristic purposes and its consequences, that needed to be considered along the touristic planning.

Keywords: Tourism. Theory of Tourism. Tourism Planning. 


\section{CONSIDERAÇÕES INICIAIS}

O turismo moderno utiliza teorias relacionadas a diversas áreas do conhecimento, sendo objeto de estudo da economia, história, geografia, sociologia, e em especial do próprio turismo. Dada às proporções do desenvolvimento da atividade turística e o grau de importância que possui na sociedade, faz-se necessário à construção do conhecimento no campo de estudo sobre essa prática, caráter que evidencia a multi, inter e transdisciplinaridade do turismo.

Teorias derivadas de áreas afins possibilitam o conhecimento e identificaram as lacunas existentes no saber turístico. No entanto, a delimitação conceitual do turismo é um esforço feito, sobretudo no campo específico de estudo do turismo, já que as ciências que procuram analisar o turismo o fazem muita mais focadas em suas teorias e conceitos, algumas vezes negligenciando tal conceituação. Já no caso das teorias de planejamento turístico, que se detinham mais ou menos em determinadas áreas específicas. O principal resultado disso é que por mais que se reconheça o planejamento turístico como área prioritária para o desenvolvimento dos destinos, há uma grande distância entre o que é planejado e o que é implementado.

Neste sentido, o objetivo deste trabalho é analisar aspectos conceituais relacionados às teorias sobre turismo e planejamento turístico, compreendendo as concepções de turismo utilizadas por autores brasileiros que apontam em suas pesquisas etapas de planejamento do turismo em obras sobre este tema específico.

O trabalho pretende contribuir para o debate atual que se estabelece sobre os aspectos epistemológicos, teóricos e conceituais e que visam ao mesmo tempo a compreensão das possibilidades e das limitações da compreensão do fenômeno do turismo e os modos de atuação para o planejamento dessa atividade, sua ressignificação a partir da evidência de suas amplitude e complexidade.

Utilizou-se os procedimentos metodológicos de levantamento bibliográfico e análise do conteúdo das principais obras sobre planejamento turístico de autores brasileiros com grande utilização na formação de profissionais turismólogos e que embasam muitas das pesquisas sobre o tema realizadas no Brasil. Especificamente, foram analisadas as obras de Barretto (1991), Ruschmann (1997), Beni (1998) e Dias (2003). 
As novas tendências do turismo de acordo com Ansarah (2001,) seguem enfatizando a necessidade tanto da qualidade da experiência proporcionada aos turistas como também a relacionada ao destino, exaltando cada vez mais a melhoria da qualidade de vida das comunidades receptoras, sendo este o maior desafio da atividade turística. Medeiros (2003, p. 14) expõe a relevância do planejamento para o desenvolvimento do turismo em tempos atuais. Para ele, "o turismo do século XXI não permite mais improvisações ou esquemas amadorísticos. Há necessidade de profissionalismo e planejamento face às novas exigências da demanda". Esse imperativo é justificável, sobretudo no contexto das diversas análises sobre as consequências do desenvolvimento do turismo nas localidades receptoras.

Desse modo, a principal contribuição deste trabalho, diante da bibliografia que estabelece conceitos e etapas do planejamento turístico, é a necessidade da discussão sobre a conceituação de turismo que embasam tal proposição, uma vez que, a preocupação teórica e crítica com o conceito de turismo devem anteceder as análises empreendidas pelo campo científico que o estuda.

\section{ASPECTOS CONCEITUAIS DE TURISMO EM OBRAS SOBRE PLANEJAMENTO TURÍSTICO}

Dentre os autores brasileiros que escrevem sobre turismo, são foco deste trabalho aqueles que têm sua obra voltada para questões em que possam ser estabelecidas relações entre suas concepções acerca do conceito de turismo e seus entendimentos sobre planejamento turístico. Além disso, foi considerado como critério de seleção dos autores e das obras analisadas a ampla utilização na formação dos profissionais turismólogos e pesquisas sobre o tema no Brasil. Serão analisados quatro autores brasileiros que foram selecionados pela proximidade e pelas publicações com os temas em estudo.

Margarita Barretto é doutora em educação pela Universidade Estadual de Campinas (UNICAMP), turismóloga e pesquisadora nível $1 \mathrm{C}$ do Conselho Nacional de Desenvolvimento Científico e Tecnológico (CNPQ). Sua contribuição aos estudos do turismo está voltada para a epistemologia, planejamento e patrimônio. Trabalha a turismologia como forma de estudar e entender o fenômeno turístico e fundamenta suas pesquisas nas áreas de cultura, patrimônio e antropologia do turismo.

Para Barretto (1991, pp. 47-48), “o turismo é essencialmente movimento de pessoas e atendimento às suas necessidades, assim como às necessidades das outras pessoas que 
viajam. O turismo é o fenômeno de interação entre o turista e o núcleo receptor e de todas as atividades decorrentes dessa interação". Essas relações permitem que o indivíduo se distancie de seu cotidiano.

Doris Van de Meene Ruschmann é doutora em ciências da comunicação pela Escola de Comunicações e Artes da Universidade de São Paulo (ECA/USP) tendo seus estudos e publicações relacionadas com a área do planejamento e sustentabilidade do turismo. A autora defende a ideia de que as ações planejadas resultam em menor impacto no desenvolvimento de um turismo que seja favorável para os empreendedores, populações receptoras e turistas.

Quanto ao conceito de turismo, apesar de não apresentar um conceito novo ou com uma abordagem própria pode-se entender sob a sua ótica, o turismo como sendo parte integrante do estilo de vida de um número crescente de pessoas em todo o mundo. Que viajam para satisfazer suas necessidades, que vão desde a recreação ativa ou passiva, conferências e reuniões, a passeios ou negócios, onde utiliza uma variedade de equipamentos e serviços criados para seu uso e satisfação. A experiência turística pode acontecer em diferentes lugares, entre eles regiões costeiras, campos, montanhas, lagos, rios, etc. O seu acontecimento pressupõe tempo livre.

O professor Mário Carlos Beni, doutor em ciências da comunicação e Livre Docente em Turismo pela Escola de Comunicações e Artes da Universidade de São Paulo (ECA/USP); tem seus estudos no turismo voltados a compreensão do fenômeno enquanto sistema. A partir da criação do Sistema de Turismo, este teórico explica as relações entre os vários subsistemas do turismo, dando ênfase ao caráter holístico da atividade e suas interrelações com o meio. Assim, para Beni (1998, p. 36), turismo "é o estudo do homem longe de seu local de residência, da indústria que satisfaz suas necessidades, e dos impactos que ambos, ele e a indústria, geram sobre os ambientes físicos, econômicos e socioculturais da área receptora".

Em seu olhar, o planejamento turístico faz parte do Conjunto das Relações Estruturais do SISTUR, no subsistema da Superestrutura, que é responsável pelas Políticas, Planejamento e Gestão do turismo. O autor ainda contribuiu para os estudos na área de planejamento, em sua obra "Globalização do Turismo: Megatendências do Setor e a Realidade Brasileira", em que indica a formação de clusters, como estratégia competitiva para o planejamento dos destinos turísticos.

O sociólogo Reinaldo Dias, tem estudos voltados para o turismo direcionando suas discussões para o fenômeno e sua interface com a sociologia, patrimônio, meio ambiente, metodologias e aqui em destaque para o planejamento turístico. Sua abordagem sobre 
planejamento conferiu ao seu livro "Planejamento do Turismo: política e desenvolvimento do turismo no Brasil", grande circulação, debate e uso entre alunos, professores e demais atores públicos e privados do trade turístico. Dias (2003, p.45) adota em sua obra, o conceito de turismo da Organização Mundial do Turismo [OMT](2001):

\footnotetext{
É o conjunto de atividades que as pessoas realizam durante suas viagens e estadas em lugares diferentes ao de seu entorno habitual, por um período de tempo consecutivo inferior a um ano, com o objetivo de lazer, negócios ou outros motivos, não relacionados com uma atividade remunerada no lugar visitado. Importante assinalar que o turismo compreende todas as atividades dos visitantes, tanto de turistas como de excursionistas.
}

Apesar de reconhecer a relevância e aplicabilidade de sua proposta, associar-se ao conceito da OMT (2001) é difundir uma visão reducionista - para alguns autores - que extraia seu viés econômico, e seus interesses estatísticos, prezando pela valoração da produção turística, os índices e números das contas nacionais, transações internacionais e crescimento econômico, além de estudos de fluxo turístico e seu potencial transformador. Ao enfatizar seu lado econômico, destacando fatores como "deslocamento", "estada"e "enquadramento de tempo de permanência", o conceito recai sobre alguns elementos específicos da experiência, mas não sobre as interrelações causadas pelo fenômeno social do turismo.

\section{METODOLOGIA}

De abordagem qualitativa e caráter exploratório, esta pesquisa se debruça sobre uma reflexão teórico-conceitual, baseada na produção bibliográfica de autores brasileiros que apresentam em suas análises diretrizes para o planejamento turístico, para além de concepções acerca do conceito de turismo no qual acreditam. $\mathrm{O}$ artigo se apresenta propondo um diálogo que manifeste a importância dessas pesquisas e a consolidação das discussões epistemológicas acerca do fenômeno turístico. Buscando emoldurar uma análise comparativa entre obras e evidenciar a relação entre as definições dos autores sobre o conceito de turismo. Tanto a partir das dimensões do espaço de deslocamento, tempo de permanecia em viagem, práticas do turista, mas também da própria essência abordada desse conceito (atividade econômica, prática social, experiência individual etc.), além das estruturas de planejamento da atividade turística proposta pelos autores. 


\section{ANÁLISE E DISCUSSÕES DOS RESULTADOS}

\subsection{Aspectos conceituais de planejamento turístico}

O raciocínio é a principal característica que diferencia os seres humanos dos demais animais. $\mathrm{O}$ ato de pensar faz com que o homem esteja sempre buscando sanar suas necessidades. No livro O Ócio Criativo, De Masi (2000) afirma que o homem começou a planejar quando descobriu a semente, seis mil anos antes de Cristo. Por meio desta descoberta o homem aprende a programar suas ações e planejar o futuro, pois sabe que se trabalhar hoje garantirá o alimento em determinado espaço de tempo. Ao processo de estabelecer objetivos, escolher a melhor maneira de alcançá-los e, sobretudo, avaliar as consequências e resultados das escolhas, dá-se o nome de planejamento, sendo este conceituado por diversos autores.

No que tange ao planejamento turístico é preciso considerar a complexidade da atividade turística e a gama de variáveis envolvidas. Os autores, foco deste trabalho, apresentam seus conceitos de planejamento turístico, baseando-se no entendimento particular que cada um tem da área. A busca de resultados positivos e a possibilidade de se alcançar um futuro desejado faz com que o conceito de planejamento seja demasiadamente utilizado na atividade turística, fazendo com que este processo seja amplamente discutido por estes estudiosos da área.

O planejamento é um processo ativo e, conforme Barretto (1991), é uma atividade dinâmica, não é estático, e possui muitos fatores concomitantes que necessitam ser analisados e coordenados para se alcançar um objetivo possível e satisfatório. É um processo que precisa ser constantemente repensado após o alcance dos objetivos traçados. Nessa perspectiva, planejamento é a organização sistemática de um conjunto de ideias e decisões, de forma integrada. Consiste na definição de objetivos, ordenação dos recursos materiais e humanos, na determinação de métodos, tempo, indicação de localização espacial. É uma ação voltada para o futuro.

Nesse sentido, ainda segundo Barretto (1991), quando se trabalha com planejamento de turismo, é importante uma maior sistemática, pois o turismo implica o fluxo de pessoas, receptividade. E nessa relação, há circulação de receita, construção de equipamentos e oferta de serviços de apoio. Assim, planejamento requer pesquisa social, pessoal qualificado, compreensão do problema e conhecimento de métodos científicos. 
Para Ruschmann (2001, p. 66) "é a partir do planejamento que é possível estabelecer condições favoráveis para alcançar objetivos propostos". Ainda para esta autora a finalidade do planejamento turístico está em ordenar as ações humanas sobre uma localidade turística, bem como direcionar a construção de equipamentos e facilidades, de forma adequada, evitando efeitos negativos nos recursos que possam destruir ou afetar sua atratividade. $\mathrm{O}$ planejamento turístico também está vinculado a uma transformação previamente orientada pelos interesses da comunidade.

Na visão de Beni (1999, p. 12),

\begin{abstract}
planejamento é o processo de interferir e programar os fundamentos definidos do turismo que, conceitualmente, abrange em três pontos essenciais e distintos: estabelecimento de objetivos, definição de cursos de ação e determinação da realimentação, já que a atividade apresenta enorme interdependência e interação de seus componentes.
\end{abstract}

Dias (2003), apesar de não conceituar o planejamento, utiliza os conceitos de Bromley (1982), Rattner (1979) e Barreto (1991) para justificar as suas proposições acerca do planejamento turístico. $\mathrm{O}$ autor afirma que existem inúmeras abordagens sobre o tema em estudo e que cada autor utiliza as definições que lhe for conveniente. Em suas reflexões, afirma que em qualquer sociedade planejar é uma tentativa de definir e seguir uma direção desejada. Dias (2003, p.88), afirma que, quando se planeja, visa-se "adequar os meios aos objetivos enunciados". É importante perceber que o planejamento não é estático. Ele varia conforme a realidade onde está inserido.

Além dos autores em estudo neste trabalho, diversos outros autores também têm como objeto de estudo a temática do planejamento turístico e tentam uma aproximação conceitual acerca do tema. É o caso, por exemplo, de Molina e Rodriguez (2001, p.78) "o planejamento é o resultado de um processo lógico de pensamento, mediante o qual o ser humano analisa a realidade abrangente e estabelece os meios que lhe permitirão transformá-la de acordo com seus interesses e aspirações".

Petrocchi (1998, p.19) afirma que "planejamento é a definição de um futuro desejado e de todas as providências necessárias à sua materialização". Consequentemente o ato de planejar está diretamente vinculado a um futuro desejado. A OMT (2003b, p. 41) diz que "planejar é organizar o futuro de forma a atingir certos objetivos. O planejamento oferece um guia para a tomada de decisões por ações futuras".

Há certa similaridade nos conceitos que envolvem o planejamento, destacam-se algumas palavras que pressupõe o ato de planejar, tais como: método, processo, futuro, objetivos, e ordenação de ações. O método é a ordem que se deve impor aos diferentes 
processos para atingir uma finalidade ou resultado desejado. O processo é o conjunto de normas, práticas do agir, meios empregados na aplicação do método, conforme Petrocchi (1998).

O resultado de um processo de planejamento está sempre vinculado a um futuro desejado. Ao se estabelecer o cenário que representa o futuro desejado, seja ele qual for, torna-se possível determinar os objetivos a serem alcançados para que este cenário se concretize. Somente com a determinação dos objetivos é que será possível estabelecer a complexidade do processo de planejamento.

Quanto mais complexo for o objetivo a ser alcançado, mais complexo será o processo de planejamento e consequentemente, será possível ordenar prioritariamente as ações a serem executadas de modo a alcançar os resultados esperados.

\footnotetext{
A ação de planejar implica basicamente numa intervenção deliberada, tendo como base o conhecimento racional dos processos socioeconômicos, que permitem uma transformação de uma região de acordo com os interesses e as aspirações de desenvolvimento da comunidade. (Medeiros, 2003, p. 78).
}

Molina e Rodriguez (2001, p.81) tratam o planejamento turístico como essencial para a sustentabilidade da atividade turística e indica que este "é um processo sistemático e flexível, cujo único fim consiste em garantir a consecução dos objetivos que, sem este processo, dificilmente poderiam ser alcançados".Hall (2001, p.24) sustenta que o processo de planejamento turístico não está apenas vinculado à simples tomada de decisão. Este não trata apenas de decidir o que deve ser oferecido no futuro de uma comunidade. "O planejamento turístico é um tipo de tomada de decisões e elaboração de políticas, portanto, lida com um conjunto de decisões interdependentes ou sistematicamente relacionadas e não com decisões individuais".

A interdependência deve ser considerada já na composição do conceito de planejamento turístico, de modo a evidenciar que o turismo é um sistema e por isso tem um grau de complexidade elevado, uma vez que considera a interdependência e as interrelações de seus componentes. Esta interdependência da atividade turística eleva o grau de complexidade do processo de planejamento e faz necessária a inclusão da palavra flexibilidade no conceito de planejamento turístico. A flexibilidade é uma condição relevante uma vez que privilegia o respeito às características locais, permitindo adaptar o método em função destas características e não ao contrário. 


\subsection{O processo de planejamento turístico e suas etapas}

Para determinar qual o melhor método a ser aplicado na elaboração de um planejamento de um destino turístico é necessário que se considere a área de abrangência deste planejamento. O planejamento do destino é usado para referenciar esse processo desenvolvido para uma região geográfica que possua os elementos como instalações, atrativos, infraestrutura e profissionais suficientes para atrair visitantes e para a realização de atividades turísticas, podendo ter abrangência internacional, nacional, regional ou local (OMT, 2003a).

Quanto maior o nível de abrangência do planejamento, mais complexo este será, uma vez em que se aumentando a escala geográfica, também se aumentam as variáveis relacionadas à cadeia produtiva do turismo envolvidas no processo. Por exemplo, ao planejar um destino turístico na esfera municipal, as variáveis estão limitadas à divisão políticaadministrativa do município em questão.

Por outro lado, o planejamento de um destino turístico em nível regional, já amplia estas variáveis, pois os objetivos de uma região são mais complexos, envolvendo não só as diferenças relativas às características dos locais em questão, mas também os interesses políticos e privados. Além dos níveis de abrangência há que se considerar que, para que o planejamento turístico esteja baseado em um processo lógico, faz-se necessária a sistematização de suas etapas. A aplicação destas etapas independe do nível de abrangência e variam de autor para autor.

A decisão de planejar é motivada por diversas necessidades conjunturais e estruturais, nos mais diversos setores. Barretto (1991) afirma que, no caso do turismo, urge a necessidade de sistematizar e adaptar o movimento turístico ao destino e, ainda, atender às expectativas da demanda, contemplando os direitos dos moradores, no que se refere à urbanização, meio ambiente, cultura e relações sociais. Dessa forma, do ponto de vista processual, é importante estabelecer etapas para efetivação do processo de planejamento turístico.

Barretto (1991) indica cinco etapas a serem trabalhadas no planejamento:

a) Estudo diagnóstico: trata da investigação, reflexão e compreensão da realidade bem como identificação de fatos e tendências; 
b) Definição de objetivos: é a tomada de decisão em que se definem o estado das coisas que se pretende atingir com a ação planejada. É preciso clareza e legitimação;

c) Implantação e execução: instalação, execução e funcionamento do empreendimento. É a ação;

d) Controle: acompanhamento com vistas à verificação da correspondência com o planejado, identificação e correção de desvios e/ou bloqueios e fornecimento de subsídios para a etapa seguinte;

e) Avaliação do trabalho: uma crítica pura ou orientada para um replanejamento. Deve considerar não apenas os resultados, mas também a efetivação dos objetivos. O desempenho de todo o projeto é analisado.

As etapas propostas por Ruschmann (1999) referem-se a:

a) Caracterização geral do ambiente, onde é realizado o levantamento dos aspectos gerais, geográficos, econômicos e sociais da região objeto de estudo;

b) Inventário turístico, sendo este o levantamento das condições naturais, culturais, infraestrutura turística, recursos humanos para o turismo e caracterização da demanda, e por fim;

c) Análise e/ou avaliação, que se refere à análise dos pontos fortes e fracos, diagnóstico, prognóstico e diretrizes.

Beni (1998) classifica as etapas do planejamento turístico como:

a) Estudo preliminar, onde é feita toda a caracterização do local;

b) Diagnóstico, onde é feita a análise dos dados levantados na etapa anterior; e

c) Prognóstico, que na visão do autor seria uma tentativa de previsão de futuro embasada pelo conhecimento da realidade para posterior proposição de diretrizes.

Na visão de Dias (2003), o planejamento está alinhado a uma concepção funcionalista do turismo difundida pela OMT. Atentando para uma percepção de planejamento turístico que direciona para etapas que otimizem a dinâmica e louros da atividade -com bons resultados para experiência do visitante e para o destino visitado, sua concepção de turismo vincula suas etapas de planejamento:

a) Decisão de planejar;

b) Conteúdo do plano - destaque para prognóstico, e; 
c) Implementação do plano ao funcionalismo da OMT.

Mesmo que pertencendo à sequência aparentemente lógica, cabe aqui uma ponderação no sentido de questionar se a etapa de prognóstico, da forma como é concebida pelos autores, não deveria passar por uma revisão. Uma vez que ela é baseada no conhecimento da realidade de um local, mas que esta realidade faz parte de um contexto que é dinâmico, e assim passível de muitas mudanças. Este cenário faz com que um processo de planejamento baseado em previsões, corra riscos de ter que corrigir muitas falhas e em pouco tempo ficar obsoleto.

As etapas que compõem o processo de planejamento, em linhas gerais, pressupõem em sua essência o profundo conhecimento da realidade do objeto de estudo em questão, a análise imparcial desta realidade que, por sua vez, delineará as ações prioritárias a serem implementadas na região em questão. Estas etapas levam a conclusão da primeira parte do processo de planejamento turístico que é a elaboração do plano, do documento físico que contem os resultados provenientes da execução das etapas anteriores.

No processo de planejamento, o plano se constitui de parte fundamental, pois nele está o ferramental que indica o que se faz necessário para o desenvolvimento turístico de uma região. Porém, o plano não se constitui no processo completo de planejamento. Depois de sua elaboração ainda há que se considerar a implementação deste. De nada adianta a elaboração do plano se as ações ali propostas não saírem da esfera documental. A ação, de colocar o plano em prática, senão em sua totalidade, mas no que for prioritário dentro dos recursos possíveis, é que se reverterá no êxito ou no fracasso de todo processo que envolve todas as etapas de planejamento turístico. O quadro 01 apresenta um resumo dos autores aqui analisados, com enfoque para o conceito de turismo em que eles se aportam e as etapas de planejamento que propõe. 
Quadro 01: Abordagem conceitual de turismo proposto pelos autores brasileiros e as etapas de planejamento

\begin{tabular}{|c|c|c|c|}
\hline AUTOR & CONCEITO DE TURISMO & $\begin{array}{c}\text { ETAPAS DO } \\
\text { PLANEJAMENTO }\end{array}$ & DESCRIÇÃO DAS ETAPAS \\
\hline \multirow{5}{*}{ Barretto } & \multirow{5}{*}{$\begin{array}{l}\text { O turismo é movimento de } \\
\text { pessoas e atendimento às suas } \\
\text { necessidades. É o fenômeno de } \\
\text { interação entre o turista e o } \\
\text { núcleo receptor e de todas as } \\
\text { atividades decorrentes dessa } \\
\text { interação. }\end{array}$} & 1.Estudo diagnóstico & $\begin{array}{l}\text { Investigação, reflexão, compreensão } \\
\text { juízo dos dados da realidade bem como } \\
\text { identificação de fatos e tendências. }\end{array}$ \\
\hline & & $\begin{array}{l}\text { 2.Definição de } \\
\text { objetivos }\end{array}$ & $\begin{array}{l}\text { Definição do estado das coisas que se } \\
\text { pretende atingir com o planejamento }\end{array}$ \\
\hline & & $\begin{array}{l}\text { 3.Implantação } \\
\text { execução }\end{array}$ & $\begin{array}{l}\text { Instalação e início de funcionamento do } \\
\text { empreendimento. }\end{array}$ \\
\hline & & 4. Controle & $\begin{array}{l}\text { Acompanhamento dacorrespondência com } \\
\text { o planejado, identificação e correção de } \\
\text { desvios e/ou bloqueios e fornecimento de } \\
\text { subsídios para a etapa seguinte. }\end{array}$ \\
\hline & & $\begin{array}{l}\text { 5. Avaliação } \\
\text { trabalho }\end{array}$ & $\begin{array}{l}\text { Crítica pura ou orientada para um } \\
\text { replanejamento. O desempenho dos } \\
\text { resultados é analisado. }\end{array}$ \\
\hline \multirow{3}{*}{ Ruschmann } & \multirow{3}{*}{$\begin{array}{l}\text { O turismo é integrante do estilo } \\
\text { de vida de um número crescente } \\
\text { de pessoas em todo o mundo } \\
\text { que viajam para satisfazer suas } \\
\text { necessidades, que vão desde a } \\
\text { recreação ativa ou passiva, } \\
\text { conferências e reuniões, } \\
\text { passeios ou negócios, onde } \\
\text { utiliza uma variedade } \\
\text { equipamentos e serviços criados } \\
\text { para seu uso e satisfação. } \\
\text { Pressupõe tempo livre. }\end{array}$} & $\begin{array}{l}\text { 1.Caracterização } \\
\text { geral }\end{array}$ & $\begin{array}{l}\text { Levantamento dos aspectos gerais, } \\
\text { geográficos, econômicos e sociais da } \\
\text { região objeto de estudo. }\end{array}$ \\
\hline & & $\begin{array}{l}\text { 2.Aspectos } \\
\text { turísticos } \\
\text { (inventário } \\
\text { turístico) }\end{array}$ & $\begin{array}{l}\text { Levantamento das condições naturais, } \\
\text { culturais, infraestrutura turística, recursos } \\
\text { humanos e caracterização da demanda. }\end{array}$ \\
\hline & & $\begin{array}{l}3 . \\
\text { Análise/avaliação }\end{array}$ & $\begin{array}{l}\text { Análise dos pontos fortes e fracos, } \\
\text { diagnóstico, prognóstico e diretrizes. }\end{array}$ \\
\hline Beni & Turismo é o estudo do homem & 1. Estudo preliminar & $\begin{array}{l}\text { Levantamento e cadastramento de todas as } \\
\text { características do local }\end{array}$ \\
\hline
\end{tabular}




\begin{tabular}{|c|c|c|c|}
\hline & $\begin{array}{l}\text { longe de seu local de residência, } \\
\text { da indústria que satisfaz suas }\end{array}$ & 2. Diagnóstico & $\begin{array}{l}\text { Análise dos dados levantados no estudo } \\
\text { preliminar. }\end{array}$ \\
\hline & $\begin{array}{l}\text { que ambos, ele e a indústria, } \\
\text { geram sobre os ambientes } \\
\text { físicos, econômicos } \\
\text { socioculturais da área receptora. }\end{array}$ & 3. Prognóstico & $\begin{array}{l}\text { Previsão de um futuro próximo baseado na } \\
\text { realidade encontrada e a proposição de } \\
\text { diretrizes. }\end{array}$ \\
\hline \multirow{4}{*}{ Dias } & \multirow{4}{*}{$\begin{array}{l}\text { É o conjunto de atividades que } \\
\text { turistas e excursionistas } \\
\text { realizam durante suas viagens e } \\
\text { estadas em lugares diferentes ao } \\
\text { de seu entorno habitual, por um } \\
\text { período de tempo inferior a um } \\
\text { ano, com o objetivo de lazer, } \\
\text { negócios, não relacionados com } \\
\text { uma atividade remunerada. }\end{array}$} & $\begin{array}{l}\text { 1.Levantamento da } \\
\text { situação } \\
\text { (diagnóstico) }\end{array}$ & $\begin{array}{l}\text { Coleta dados, análise das informações } \\
\text { obtidas e da situação atual. }\end{array}$ \\
\hline & & $\begin{array}{l}\text { 2.Análise do que } \\
\text { será planejado }\end{array}$ & $\begin{array}{l}\text { Identificar as alternativas possíveis, } \\
\text { formulando hipóteses e propondo } \\
\text { diferentes modelos de desenvolvimento. }\end{array}$ \\
\hline & & $\begin{array}{l}\text { 3.Elaboração do } \\
\text { plano }\end{array}$ & $\begin{array}{l}\text { Critérios e diretrizes gerais do } \\
\text { desenvolvimento que deverão ser seguidos } \\
\text { nos planos setoriais e nos projetos e } \\
\text { programas específicos. }\end{array}$ \\
\hline & & $\begin{array}{l}\text { 4.Implantação do } \\
\text { plano }\end{array}$ & $\begin{array}{l}\text { Colocação do plano em prática, estando } \\
\text { sempre presentes a questão da participação } \\
\text { em grande escala. }\end{array}$ \\
\hline
\end{tabular}

Fonte: elaboração própria, 2014.

Observamos uma diversidade de concepções de turismo utilizadas pelos autores analisados, que variam, por exemplo, de entendimentos desse fenômeno como uma atividade comercial. O que implica que o planejamento turístico deve ser o ordenamento do arranjo produtivo, para a dinamização econômica do turismo. E, por outro lado, de uma concepção do turismo como atividade humana, que envolve, além de sua dimensão econômica, aspectos socioculturais da interação visitado-visitante, usos turísticos da cultura e do ambiente locais, com suas consequências, que devem ser considerados no planejamento turístico. 


\section{CONSIDERAÇÕES FINAIS}

Apesar de o tema planejamento turístico fazer parte da pauta dos discursos políticos e ser objeto de estudo de conceituados pesquisadores da área de turismo é preciso reconhecer que, na prática, são poucos os exemplos que obtiveram êxito no processo. Um dos aspectos que mais dificultam o êxito do planejamento turístico é a maneira isolada como este é elaborado. Os fatores que dificultam o êxito são consequência das implicações da complexidade da atividade turística e em linhas gerais estão relacionados aos métodos utilizados. A construção do processo de planejamento turístico envolve variáveis econômicas, sociais, cultural, ambientais e políticas.

Para os autores estudados neste trabalho e suas concepções sobre turismo e planejamento turístico. Fica claro que mesmo encontrando cenários com os quais na maioria das vezes só se pode trabalhar com a postura reativa (devido ao crescimento rápido e espontâneo da atividade turística), o planejamento deve também ser proativo no que diz respeito ao conhecimento do meio em que está inserido a ponto de chegar ao máximo de precisão possível.

A postura proativa está baseada no profundo conhecimento do objeto de estudo e por isso maximiza os efeitos positivos da atividade turística, possibilitando a escolha do tipo de desenvolvimento que a região quer e necessita. Enquanto isso, o processo de planejamento deve ser flexível a ponto da postura reativa ser adotada quando houver o descontrole ou o erro de previsão envolvendo alguma variável pertinente ao processo.

Há que se considerar que o entendimento do que é planejamento, se refere principalmente à informação particularizada do que seja o planejamento turístico em sua totalidade. O que se verifica na prática é que de acordo com os interesses envolvidos, o planejamento ganha ênfases diferenciadas, como se fossem vários processos diferentes e não uma continuidade.

Não observamos uma preocupação dos autores analisados em realizar uma profunda discussão sobre a ampla e complexa conceituação de turismo, para propor teorias e etapas do planejamento dessa prática. Nesse estudo, o turismo aparece como uma atividade ampla e supervalorizada, envolvendo toda a diversidade de atividades, estruturas e facilidades utilizadas quando pessoas deslocam-se, sobretudo relacionadas ao lazer. A partir dessa conceituação superficial, o planejamento proposto corresponde a preparação dos lugares para receber os fluxos de pessoas em viagem e a para a instalação da rede de organizações e serviços que comercialização produtos a esses viajantes (turistas ou não). 
Podemos refletir, então, se a preocupação com a definição clara do que é turismo seria um dos fatores a garantir maior eficácia para o planejamento turístico, já que sem tal definição podemos centrar esforços em dimensões que não necessariamente estão diretamente ligadas à atividade turística, ou partindo de uma definição específica de turismo, poderíamos descentralizar políticas de preparação dos destinos para outras políticas setoriais, como mobilidade urbana, lazer etc.

\section{REFERÊNCIAS}

Ansarah, M. (2001). Teoria Geral do Turismo. In Ansarah, M. (Org.). Turismo. Como aprender, como ensinar. (Vol. 2). São Paulo: Senac.

Barretto, M.(1991). Planejamento e organização em turismo. Campinas: Papirus.

Beni, M. (1998). Análise estrutural do turismo. São Paulo: Senac.

Beni, M. (1999). Política e estratégia do desenvolvimento regional: planejamento integrado e sustentável do turismo. Turismo em Análise, 10(1), 7-17.

Beni, M. (2001). A Política do Turismo. In Trigo, L. (Org.). Turismo. Como aprender, como ensinar. (Vol. 1). São Paulo: Senac.

Beni, M. (2003). Globalização do turismo: megatendências do setor e a realidade brasileira. São Paulo: Aleph.

Bromley, R. (1982). O processo de planejamento: lições do passado e um modelo para o futuro. In: R. Bromley, \& E. Bustelo. (Orgs.). Política $x$ técnica no planejamento: perspectivas críticas. São Paulo: Brasiliense / Unicef.

De Masi, D. (2000). O ócio criativo. São Paulo: Sextante.

Dias, R. (2003). Planejamento do turismo

o Paulo: Atlas.

Hall, C. (2001). Planejamento Turístico: políticas, processos e relacionamentos. São Paulo: Contexto.

Medeiros, F. (2003). Considerações Gerais Sobre o Planejamento Turístico Regional. In Reis, F. (Org.). Turismo, uma perspectiva regional. Taubaté: Cabral.

Molina, S., Rodriguez, S. (2001). Planejamento Integral do Turismo: um enfoque para a América Latina. Bauru: Edusc.

Organização Mundial do Turismo. (2001). Introdução ao Turismo. São Paulo: Roca. 
Organização Mundial do Turismo. (2003a). Turismo Internacional: uma perspectiva global. Porto Alegre: Bookman.

Organização Mundial de Turismo. (2003b). Guia de Desenvolvimento do Turismo Sustentável. Porto Alegre: Bookman,.

Petrocchi, M. (1998). Turismo, Planejamento e Gestão. São Paulo: Futura.

Rattner, H. (1979). Planejamento e bem-estar social. São Paulo: Perspectiva.

Ruschmann,D. V. de M. (1997). Turismo e Planejamento Sustentável: A proteção do meio ambiente. Campinas,São Paulo: Papirus

Ruschmann, D. (1999). Turismo e Planejamento Sustentável: a proteção do meio ambiente. Campinas: Papirus.

Ruschmann, D. (2001). Planejamento Turístico. In Ansarah, M. (Org.). Turismo. Como aprender, como ensinar. (Vol. 2). São Paulo: Senac. 